\title{
Maritime Stock Prices and Information Flows: A Cointegration Study
}

\author{
Joshua Shackman, Paul Lambert, Phoenix Benitiez, Nathan \\ Griffin, David Henderson
}

In this study, the issue of how global maritime stock prices influence the stock prices of large transportation companies in the U.S. and other large markets is examined. Maritime stocks are chosen because they are central in global trade and thus may be good indicators of future global stock market and economic trends. Maritime companies are often owned by families or governments and are traded in stock markets with lower standards of accountability, hence information flows from maritime stocks may be slower than flows from other stocks. Cointegration and vector error-correction analysis is used to analyze the short-term and long-term relationships between maritime stocks, rail stocks, and trucking stocks. Evidence is found of a gradual diffusion of information from maritime stock prices to large rail or trucking stocks. This suggests that price changes in maritime stocks may help predict changes in prices in non-maritime transportation stocks.

\section{KEY WORDS}

$\sim$ Maritime stocks

$\sim$ Stock price prediction

$\sim$ Cointegration

$\sim$ Corporate governance

\section{California State University, Maritime Academy, Vallejo, US \\ e-mail: jshackman@csum.edu \\ doi: 10.7225/toms.v10.n02.018 \\ This work is licensed under (cc) BY}

Received on: 28.05.2020 / Revised on: 16.10.2021/Accepted on: 18.10.2021/ Published: 21.10 .2021

\section{INTRODUCTION}

Few industries are more central to international trade than the maritime sector, as over $90 \%$ of international trade is done through ocean shipping (International Maritime Organization, 2020). The maritime industry is also unique in that despite its large size, leadership in this sector often comes from smaller countries such as Greece, Singapore, Norway, and South Korea, with shipping of the U.S. and U.K. playing a surprisingly modest role. In addition, ownership of even the largest companies tends to be concentrated in the hands of a single family. But despite the central importance of the maritime industry and its unique global ownership structure, very little research has been done on maritime stocks.

Giannakopoulou, et al. (2016) point out that despite the large size of the maritime sector, family ownership is common in many countries that have large shipping industries. For example, despite Denmark's AP Moller-Maersk being the world's largest container shipping company, it still has over $50 \%$ of its voting shares controlled by a holding company owned solely by the founding family. The Mediterranean Shipping Company and CMA CGM Group are the second and third largest shipping companies in the world respectively, but both are majorityowned and operated by the founding families. None of the top twenty shipping companies are traded on U.S. stock exchanges, perhaps because foreign stock exchanges can be more conducive to family-controlled companies.

Even those shipping companies listed on American stock exchanges are often controlled by the founding family. Syriopoulos and Tsatsaronis (2011) find that Greek shipping firms listed in U.S. stock markets follow a model of corporate 
governance similar to maritime companies listed on non-U.S. stock exchanges. $80 \%$ of these Greek shipping firms were found to have a CEO from the founding family, and on average the board of directors controlled $28 \%$ of the shares.

The fact that many of the leading maritime shipping companies are family-owned and headquartered in dispersed countries has several implications as to how their stock prices may behave. First of all, family ownership and control may lead to information being closely held and not widely released to the public. This may slow information available to stock traders and slow information flows, leading to a lack of market efficiency. Also, maritime stocks are traded in different stock exchanges around the world rather than on the major U.S. stock exchanges, which may also slow information flows. Valuable information about future trends in the global transportation industry may be embedded within maritime stock prices, and this information could be useful to predict future stock prices in other transportation companies, such as truck and rail companies. Since these flows may be slow rather than instant, changes in maritime stock prices may predict future changes in rail or trucking stocks, but with a slow rather than instant adjustment period. This slow adjustment period and lack of market efficiency might mean that transportation stock prices can be predicted using maritime stock prices, allowing investors to profit from this lack of efficiency.

This study will examine whether a change in maritime stock prices can be used to predict rail or truck stock prices, as well as how far in the future they can be predicted. Due to the nature of stock market data, the chosen methods for this study are designed to distinguish between correlation and causality between maritime and other transportation stocks. In a standard linear regression, one can test the hypothesis that an independent variable $X$ has a causal impact on dependent variable $Y$. This is done through the method of ordinary least squares the slope of $X$. A significant slope for $X$ is evidence of a causal impact of $X$ on $Y$. However, if you reverse the equation and make $X$ the independent variable and $Y$ the dependent variable, you will also get a significant slope for $Y$. Hence this method alone does not help distinguish if $X$ causes $Y$. It might also be the case that $Y$ causes $X$, or there might be bidirectional causality.

As an alternative to simple linear regression, this study uses the method of Granger causality (Granger, 1969). This concept of causality presumes that the future value of $X$ cannot predict the past values of $Y$. However, Granger Causality also proposes that if past values of $X$ predict future values of $Y$, then it is evidence of a causal relationship or information flow between $X$ and $Y$. Instead of simple correlation between $X$ and $Y$, Granger uses a time series approach. In this approach it examines how past changes in $\mathrm{X}$ lead to future changes in $\mathrm{Y}$. Separate regressions can be done with current values of $Y$ as the dependent variable and past values of $X$ as the independent variable and vice versa. In this study, we examine if past changes in maritime stock prices impact future changes in rail or truck prices and vice versa using Granger Causality.

In addition to testing for Granger causality, this study examines a possible long-term equilibrium relationship between maritime, truck, and rail stocks using the concept of cointegration (Engle and Granger, 1987). Cointegration is used instead of correlation since testing for correlation between stock prices is known to be prone to spurious and unreliable results due to the random walk-type movements. Cointegration is a concept whereby stocks may appear to move randomly and independently from each other, but do not stray too far from each other and have prices that exist in equilibrium with each other.

In summary, this study examines a possible information flow of maritime stock prices to stocks of other transportation sectors. Given the corporate governance and transparency issues in the maritime industry, these information flows may be slow. To test for information flows of one or two months, Granger causality is used to see if a change in one stock price in one month leads to a change in another stock's price in the following month. For slower information flows, cointegration is used to test a long-term equilibrium relationship between stocks in different transportation sectors. While the focus of this study is the impact of maritime stock prices on stock prices in rail and trucking, the methods used also allow for testing of the opposite causal direction to see if rail and truck stock prices can predict maritime stock prices.

\section{LITERATURE REVIEW}

The unique financial risks of the maritime shipping industry have been the focus of some recent research. Yazir and Sahin (2017) find that derivatives in the maritime shipping industry can be effectively modelled through linear regression analysis, an approach that outperforms the standard Black and Scholes approaches of prior studies. Similarly, Kyriakou et al., (2017) find that a mean-reverting exponential model performs better than standard lognormal models when analyzing Baltic derivatives. The interest in financial risks of the maritime industry has extended to stock prices, where systematic risk has generally been found to be low in an extensive review of the shipping finance literature (Alexandridis et al., 2018). For example, Mohanty et al., (2021) and Drobetz et al., (2010) find that shipping stocks have overall low systematic risk as measured by beta (correlation with the market). While low betas indicate low market risk, shipping sector risk can be driven by other factors unique to the shipping industry, such as freight rate volatility (Drobetz et al., 2016; Drobetz et al., 2010) or maritime freight rates (Mohanty et al., 2021).

The finding of low systematic risk for maritime shipping stocks is just one unique aspect of these stocks. Other evidence 
of the unique nature of shipping stocks was found by Grelck et al., (2009) who found that adding shipping stocks has diversification benefits and can lead to a higher Sharpe ratio. Another unique aspect of maritime stocks is a significant opening day underpricing and longer-term underperformance of initial public offerings (Merikas et al., 2009; Merikas et al., 2010). Evidence of market inefficiency for maritime shipping stocks includes Syriopoulos and Bakos (2019), who find evidence of investor herding behavior in this sector and Abdullah et al., (2020), who find that container shipping stock behaviour is inconsistent with the efficient market hypothesis. An overall theme of the literature on shipping stocks is that they move somewhat independently on the rest of the market, and do not exhibit features of efficiently priced stocks.

Interest in the maritime industry's impact on the stock market has focused heavily on the Baltic Dry Index (BDI), which is a measure of freight rates in the global dry bulk shipping sector. Erdogan et al., (2013) find bidirectional causality between the BDI and the Dow Jones Industrial Average. Bakshi (2011) found that the BDI not only predicts global stock prices but also commodity prices and economic activity. They find informational spillovers to be time-varying and dependent on market conditions. Alizadeh and Muradoglu (2014) find that the BDI can be used to predict U.S. stock prices, which they attribute to gradual information diffusion. More recently Manoharan and Visalakshmi (2019) find that the BDI can significantly predict stock price movements in China, and Giannarakis et al., (2017) find that the BDI is positively associated with the Dow Jones Sustainability Index. Lin et al., (2019) find significant volatility spillovers between the BDI and dry bulk stock prices and Choi et al., (2019) find that the BDI has significant volatility spillovers with some sectors of the Korean stock market.

Just as the BDI can be a vital indicator of the global economy or global stock markets, it may be the case that maritime stocks transmit vital information useful for stock market investors around the world. Just as Alizadeh and Muradoglu (2014) and Xiao (2012) find a gradual diffusion of information from the $\mathrm{BDI}$, other studies have demonstrated the gradual diffusion of information from stock market returns. Rapach et al., (2013) find evidence of gradual information diffusion by demonstrating that U.S. stock market returns can predict future returns in other stock markets around the world. They attribute their result in part to the possibility of stock market traders focusing on the U.S. exchanges before giving attention to other global markets. Similarly, Lin (2015) finds that stock returns in many Asian markets can be predicted by Singapore stock market returns. Other evidence of the international gradual diffusion hypothesis has been found in a sample of firms in twenty-two emerging market countries (Finke and Weigert, 2017), and by examining information flows between the foreign exchange market and stock market returns (Hasselgren et al., 2020)
Another factor that may slow down flows of information from maritime stock prices is corporate governance. Chan and Hameed (2006) argue that family ownership or poor corporate governance may slow down information flows from stocks. Lagoarde-Segot and Lucey (2008) find that poor corporate governance is associated with market inefficiency in the emerging markets, which should also lead to slower information flows. Other literature suggests that firms with concentrated ownership have lower agency costs and thus a better information environment, and information from these stocks can be used to predict stock prices of firms with more dispersed ownership (Farooq and Aktaruzzaman, 2019). Given the high degree of ownership concentration in maritime stocks, this research suggests that information from maritime stocks may be able to predict the prices of non-maritime stocks.

Just as maritime stock prices reflect information that can predict global macroeconomic trends, business trends for a maritime company are also likely to spill over into other transportation stocks. For example, Beuthe et al., (2001, 2014) find that rail, truck, and coastal shipping are substitutes for each other using Belgian cross-cost elasticity data. On the other hand, since trucking is often used for pre and post-haul for commodities shipped on rail or sea, then trucking also represents a complement to maritime and rail shipping (Rich et al., 2011). For example, Mitchell (2000), using cross-price elasticity data from Australia, finds that rail and coastal shipping are strong substitutes, while road and coastal shipping are mild complements. Recent research on rail and road transportation has shown that the degree of substitutability varies greatly from country to country, with low degrees of substitutability in Pakistan (Khan and Khan, 2020), but a high degree of substitutability between these modes in the U.S. (McCullough and Hadash, 2019). The degree to which one mode of transportation serves as a complement or substitute for the other one likely depends on the specific route and commodity shipped. However, it is also clear that the financial fortunes of companies in one mode of transportation will affect the fortunes of companies in other modes of transportations. Hence if maritime stock prices contain information about the financial condition of the maritime industry, maritime stock prices should have predictive power for stock prices of other companies in the transportation industry.

\section{DATA}

Monthly stock price data was collected on the ten largest publicly traded marine transportation companies in the world based on the twenty-foot equivalent unit capacity of their fleet. All but two of these companies are from Asia, including three from Taiwan and three from Japan. The only non-Asian companies in the top ten are AP Moeller-Maersk, which is headquartered in Denmark, and Hapag-Lloyd, which is headquartered in Germany. 
Table 2.

Descriptive Statistics.

\begin{tabular}{llllll} 
Name & Start Date & End Date & High Price & Low Price & Annual Growth Rate \\
\hline BDI & $07 / 01 / 1999$ & $1 / 1 / 2018$ & 11440 & 317 & $0.7 \%$ \\
\hline CNI & $11 / 01 / 1996$ & $1 / 1 / 2018$ & 82.8 & 2.9 & $16.0 \%$ \\
\hline COSCO & $06 / 01 / 2005$ & $01 / 01 / 2018$ & 34.1 & 2.6 & $1.5 \%$ \\
\hline DSV & $01 / 01 / 2000$ & $1 / 1 / 2018$ & 494 & 1.7 & $20.8 \%$ \\
\hline EVERGREEN & $01 / 01 / 2002$ & $01 / 01 / 2018$ & 26.7 & 5.2 & $1.3 \%$ \\
\hline HLAG & $11 / 01 / 2015$ & $1 / 1 / 2018$ & 37.6 & 15.9 & $26.8 \%$ \\
\hline HYUNDAI & $01 / 01 / 2002$ & $1 / 1 / 2018$ & 288576 & 4665 & $-11.2 \%$ \\
\hline JBHT & $01 / 01 / 1993$ & $1 / 1 / 2018$ & 120.8 & 2.9 & $16.2 \%$ \\
\hline K-LINE & $01 / 01 / 2002$ & $01 / 01 / 2018$ & 16870 & 980 & $3.0 \%$ \\
\hline MAERSKA & $01 / 01 / 2001$ & $1 / 1 / 2018$ & 14840 & 3300 & $1.9 \%$ \\
\hline MITSUI & $01 / 01 / 2002$ & $1 / 1 / 2018$ & 18840 & 1750 & $3.7 \%$ \\
\hline NYKA & $12 / 01 / 2009$ & $1 / 1 / 2018$ & 33.6 & 13.5 & $0.7 \%$ \\
\hline UNP & $01 / 01 / 1993$ & $1 / 1 / 2018$ & 134.1 & 7.6 & $13.9 \%$ \\
\hline WANHAI & $01 / 01 / 2002$ & $1 / 1 / 2018$ & 38.6 & 5 & $4.1 \%$ \\
\hline YANGMING & $01 / 01 / 2002$ & $1 / 1 / 2018$ & 66 & 10.1 & $-4.4 \%$
\end{tabular}

\section{METHODOLOGY}

For purposes of this study, standard linear regression is not suitable. The challenge of this study is to see if maritime stock prices can predict future movements in other stocks rather than to simply find a correlation between stocks. An established method to see if past values of one variable can predict future values of another variable is Granger causality (Granger, 1969). Granger causality operates under the assumption that the future does not cause the past, but if past values of a time series variable $X$ are associated with future values of a variable $Y$, then it is evidence of causality. Under cross-sectional regression, a significant correlation between two variables may be evidence of an association, but inferences about which variable is causing which is difficult to infer. Granger causality involves time series data and involves examining how past values of one variable predict future values of one or more other variables.

Under this method, past changes in maritime stock prices will be used to predict future values of other transportation stocks. For example, suppose $\Delta \mathrm{X}_{\mathrm{t}-1}$ is last month's change in Stock $X$ 's price and $\Delta Y_{t}$ is this month's change in a Stock $Y^{\prime}$ 's price. If Granger causality holds, changes in last month's Stock X price should show a positive relationship with this month's change in Stock Y's price. On the other hand, this method could equally be done to test the opposite hypothesis, according to which changes in last month's Stock $Y$ price can predict this month's Stock X price. The simplest form of Granger causality with just two variables and a one-month lag would be:

$\Delta Y_{t}=a_{0}+a_{1} \Delta Y_{t-1}+a_{2} \Delta X_{t-1}+\mu_{t}$

$\Delta X_{t}=\beta_{0}+a_{1} \Delta Y_{t-1}+\beta_{2} \Delta X_{t-1}+\mu_{t}$

In this case, in Equation 1 the dependent variable represents changes in Stock Y's price with past values of changes in Stock $Y$ and $X$ as independent variables. The significance of coefficient a 2 can tell us if changes in $X$ lead to a change in $Y$. The reverse direction of causality can be assessed using Equation 2. The significance of $\beta 1$ can tell us if a change in $Y$ leads to a change in $\mathrm{X}$. Similar but longer forms of these equations will be used to assess the flows of information between rail, maritime, and trucking stock prices.

A limitation of Equations 1 and 2 is that they only account for short-term associations between $X$ and $Y$ and they do not account for any long-term relationship between the two variables. It may be the case that the two stocks exist in stable long-term relationship known as cointegration (Yin et al., 2017; Engle and Granger, 1987). If this is the case, it means that the 
distance between the two stocks has a long-term relationship that reverts to the mean. In this case, if two stock prices diverge too far from the equilibrium relationship, then the stocks are expected to move closer to each other in future periods to return to the equilibrium.

As a hypothetical example of cointegration, Stock $X$ and Stock $Y$ might both be moving in a random pattern that has no apparent relationship to each other. But in the long run there may exist an equilibrium where their prices cannot move too far from each other. An example of equilibrium might be that Stock $X$ must be twice the price as Stock $Y$ due to the interrelationship between these stocks. Therefore if Stock $X$ is trading for $\$ 10$ and Stock $Y$ is trading for $\$ 5$, they are at an equilibrium. If the price of Stock $X$ goes up to $\$ 12$, either it must drop back to $\$ 10$, or Stock $Y$ must increase to $\$ 6$ (or meet somewhere in between). Tests for cointegration examines whether stocks revert back to an equilibrium ratio over time.

If an equilibrium ratio is found, this ratio can also be used for causal assessment. Suppose Stock $Y$ increases to $\$ 7$. If Stock $X$ later increases to $\$ 14$ to return the equilibrium of being twice the price as Stock $Y$, it is evidence that Stock $Y$ is leading (or causing) movements in Stock X. On the other hand, if Stock Y drops back to $\$ 5$, then it is evidence that Stock $X$ is the lead stock and Stock $Y$ is the follower (or lags Stock $X$ ). If Stock $X$ and Stock $Y$ might be in the same industry or be customers of each other, so their fates may be intertwined, and their prices cannot drift too far from each other.

In order to perform a meaningful analysis of our stock price time series, it is important to check for the statistical properties of this data. Tests for cointegration and Granger causality presume the data is stationary, i.e. it is well-behaved data with a constant mean and variance over time. It is well known from prior studies that stock prices are non-stationary and follow a random walk or similar process (Danthine and Donaldson, 2014). However, by using changes in stock prices (first differences) the time series will become stationary, as the mean change in stock prices over time is usually close to zero and remains constant over time.

To test for stationarity the Phillips and Perron (1988) test was used. This is a widely used test for stationarity and it controls serial correlation through non-parametric methods. This test involves fitting the following regression model:

$Y_{t}=a+\theta_{t}+\Phi Y_{t-1}+\epsilon_{t}$

Here $Y_{t}$ is a given time series at time period regressed on the previous period's lagged value $Y_{t-1}$, $a$ is a constant, $\theta t$ is a time trend, $\Phi$ is the slope of the regression line. The Phillips-Perron test has an alternative hypothesis that $\Phi$ has an absolute value less than one, which implies that the series will converge back to the mean over time and the series will have a constant mean consistent with a stationary series. The null hypothesis of this test is that $\Phi$ has a unit root (an absolute value of one), which means that convergence to the mean will not occur and the series will be non-stationary with a time-varying mean and variance.

In addition to testing for stationarity of the individual stock prices, it is also necessary to test whether or not the long-term relationship between the different stock prices is also stationary. Stationarity of this equilibrium in this case means that the stock prices do not stray too far from each other and thus exhibits cointegration. To test for cointegration, the Johansen (1995) test was used. This test is commonly used, including in related maritime studies similar to this one, such as Su et al., (2019), Schramm and Munim (2021), and Kasimati and Veraros (2018). This test is similar to the Phillips-Perron test, except that it tests for stationarity across a series of variables rather than a single variable.

A vector error correction model was used to assess how each maritime stock price reacts when a rail or truck stock price moves away from a long-term equilibrium between the three stocks. To estimate the long-term relationship between these stocks, the following cointegrating equation was estimated:

$\ln M_{t}=\beta_{0}+\beta_{1} \ln R_{t}+\beta_{2} \ln T_{t}+\beta_{3} \ln B D I_{t}+E C T_{t}$

$M$ refers to the maritime stock price, $\mathrm{R}$ to the rail stock price, $\mathrm{T}$ to the truck stock price, and BDI to the Baltic Dry Index. The natural log of stock prices was used as is the common practice for time series studies, as this transforms the data into a normal distribution for stock prices (Navin, R., 2007). The coefficient $\beta 1$ represents the equilibrium ratio of a rail stock price to a maritime stock price. For example, if $\beta_{1}=2$ then rail stock prices must be twice as high as the maritime stock price to be at an equilibrium. If the rail stock price goes up more than twice as much as the maritime stock price, then either the maritime stock price must increase or the rail stock must go down to reach an equilibrium. Similarly, $\beta_{2}$ and $\beta_{3}$ represent the equilibrium ratios for truck stocks and the BDI respectively.

$E C T$ is the error term for this regression, which is referred to as the error-correction term for the purposes of this analysis. It measures the extent to which the stocks are out of the equilibrium estimated in Equation 4. If the stocks are in perfect equilibrium, then ECT will be zero. But if ECT is large, then it means the stocks are out of equilibrium and at least one stock will move to bring the stocks back to equilibrium. Since the goal is to see how stocks move in the future to past values of ECT, lagged values of ECT are estimated as follows, using the estimated values of $\beta$ coefficients from Equation 2:

$E C T_{t-1}=\ln M_{t}-\beta_{0}-\beta_{1} \ln R_{t-1}-\beta_{2} \ln T_{t-1}-\beta_{3} \ln B D I_{t-1}$ 
$\mathrm{ECT}_{\mathrm{t}-1}$ indicates the previous month's deviation from the equilibrium between the stocks. If $\mathrm{ECT}_{\mathrm{t}-1}$ equals zero, then all stocks are at their equilibrium price. But if $\mathrm{ECT}_{\mathrm{t}-1}$ is greater than or less than zero, then its impact on stock prices in the next period can be assessed. $\mathrm{ECT}_{\mathrm{t}-1}$ can be used to predict future values of maritime stock prices in the following equation:

$$
\begin{aligned}
& \Delta \ln M_{t}=a_{0}+a_{1} \Delta \ln M_{t-1}+a_{2} \Delta \ln R_{t-1}+a_{3} \\
& \Delta \ln T_{t-1}+a_{4} \Delta \operatorname{lnBD} I_{t-1}+a_{5} E C T_{t-1}+\mu_{t}
\end{aligned}
$$

$\Delta \mathrm{lnM}$ in this equation is the logged first difference of the maritime stock price for month $t$, which is a close approximation for the percentage change over the previous month. By including $\Delta \mathrm{InMT}_{\mathrm{t}-1}$ as an independent variable in this equation, the impact of the previous month's percentage change in the maritime stock price on future changes in this stock price can be assessed. Similarly, by including the percentage change in rail and truck stock prices along with the BDI as independent variables, the degree to which changes in these prices can predict future maritime stock prices can be assessed.

The coefficients $a_{1}$ through a4 represent the sensitivities to how much current maritime stock prices change in response to a previous period's stock price changes. These are shortterm changes, just for one month. $\mathrm{ECT}_{\mathrm{t}-1}$ represents a longterm variable in that it represents deviations from a long-run equilibrium that covers years rather than months of stock price movements. The $a_{5}$ coefficient for $\mathrm{ECT}_{\mathrm{t}-1}$ represents the maritime stock's long-term relationship with the other stock prices. A negative and significant $a_{5}$ would mean that the maritime stock is responsive to long-term changes in the other stock prices and would move back towards its equilibrium ratio.

Whereas Equation 6 examines whether or not past changes in stock prices can predict future changes in maritime stock prices, for the purposes of this study it is also necessary to examine whether or not maritime prices can predict rail or truck stock prices. Equations 7 through 9 are very similar to Equation 6, except that rail, truck, and the BDI change places with maritime stocks and become the dependent variable. They are variations of Equation 4 except with the dependent variables changed, but demonstrating the same independent variables:

$$
\begin{aligned}
& \Delta \ln R_{t}=a_{0}+a_{1} \Delta \ln M_{t-1}+a_{2} \Delta \ln R_{t-1}+ \\
& a_{3} \Delta \ln T_{t-1}+a_{4} \Delta \operatorname{lnBDI_{t-1}}+a_{5} E C T_{t-1}+\mu_{t} \\
& \Delta \ln T_{t}=a_{0}+a_{1} \Delta \ln M_{t-1}+a_{2} \Delta \ln R_{t-1}+ \\
& a_{3} \Delta \ln T_{t-1}+a_{4} \Delta \operatorname{lnBD} I_{t-1}+a_{5} E C T_{t-1}+\mu_{t}
\end{aligned}
$$

$$
\begin{aligned}
& \Delta \ln M_{t}=a_{0}+a_{1} \Delta \ln M_{t-1}+a_{2} \Delta \ln R_{t-1}+ \\
& a_{3} \Delta \ln T_{t-1}+a_{4} \Delta \ln B D I_{t-1}+a_{5} E C T_{t-1}+\mu_{t}
\end{aligned}
$$

Hence Equation 4 through 7 tests whether or not maritime stock prices, rail stock prices, truck stock prices, and the BDI respectively can be predicted. The direction of causality between these variables can be tested, both one-way causality as well as bidirectional causality.

\section{RESULTS AND DISCUSSION}

Results from the Phillips-Perron unit root and stationarity test can be shown in Table 3 below. Each stock was tested one at a time for the presence of stationarity, both for levels and first differences. For all stock price levels (in logs) the test statistic is not significant at the $5 \%$ level. Hence the null hypothesis of a unit root and non-stationarity cannot be rejected. However, for first differences the null hypothesis of a unit root was rejected at the $1 \%$ level in every case. This result implies stationarity for all series.

Table 3

Stationarity Tests

\begin{tabular}{lll} 
Variables & Levels & First-Differences \\
\hline InMAERSK & -2.18 & $-14.438^{* *}$ \\
\hline InEVERGREEN & -2.731 & $-16.721^{* *}$ \\
\hline InHLAG & -0.642 & $-4.844^{* *}$ \\
\hline InMITSUI & -1.922 & $-13.468^{* *}$ \\
\hline InNYKA & -2.203 & $-8.524^{* *}$ \\
\hline In YANGMING & -1.722 & $-13.595^{* *}$ \\
\hline InCOSCO & -2.201 & $-11.948^{* *}$ \\
\hline InWANHAI & -2.233 & $-16.75^{* *}$ \\
\hline InHYUNDAI & -0.186 & $-15.323^{* *}$ \\
\hline InK-LINE & -1.669 & $-13.199^{* *}$ \\
\hline InDSV & -2.787 & $-33.343^{* *}$ \\
\hline InCNI & -0.842 & $-16.192^{* *}$ \\
\hline InUNP & 0.222 & $-17.337^{* *}$ \\
\hline InJBHT & 0.086 & $-14.986^{* *}$ \\
\hline InBDI & -2.501 & $-12.517^{* *}$ \\
\hline$* *$ Significant at the $1 \%$ Level & \\
\hline Significance indicates stationarity & \\
\hline & & \\
\hline
\end{tabular}


Examples of non-stationarity versus stationarity can be seen in Figures 1 and 2 below. Figure 1 shows the logged stock prices of JBHT over time. JB Hunt's stock price has a steady upward increase over time, which is shown by the purple line. On the other hand, the monthly change in JBHT can be seen on the blue line. Instead of an upward trend, the monthly stock price change goes up and down in wide swings, but still always reverts to its mean which is slightly above zero. The black line shows the trend for monthly increases or decreases in JBHT.

Figure 2 shows the same pattern for UNP. Both UNP and JBHT have upward trends. In a regression between UNP and JBHT, one might find a strong correlation but this correlation might be due to pure chance as on average most stocks show an upward trend. The method used in this study focuses on changes rather than levels. While the blue lines for stock price changes show a much more random-looking pattern than the purple lines for stock price levels, correlations between changes in stock prices are considered far more meaningful than correlations between stock price levels (Fabozzi et al., 2014).

Now that non-stationarity in stock price levels and stationarity in stock price changes has been established, the next step is to test for cointegration - i.e. if the three stocks and the $\mathrm{BDI}$ have a long-term equilibrium with respect to each other. The long-term relationships are also estimated. When JBHT and UNP are included, all maritime stocks show a long-term relationship with the other stocks except for YANGMING. These nine stocks are shown in Table 4. When DSV and CNI were included, only five maritime stocks were shown to have a cointegrating relationship. These five stocks are shown in Table 5.

Table 4.

Equilibrium ratios between stocks.

\begin{tabular}{llll} 
Martime Stock & $\boldsymbol{\beta} \mathbf{i}(\mathbf{I n J B H})$ & $\boldsymbol{\beta 2}$ (InUNP) & $\boldsymbol{\beta} 3$ (InBDI) \\
\hline InEVERGREEN & $0.40^{* *}$ & $0.43^{*}$ & $0.33^{* *}$ \\
\hline InMAERSK & $-1154.35^{* *}$ & 539.60 & $565.52^{* *}$ \\
\hline InHLAG & $1.90^{* *}$ & $-2.89^{* *}$ & -0.13 \\
\hline InMITSUI & -0.55 & 0.59 & $1.19^{* *}$ \\
\hline InNYKA & 0.57 & 0.01 & $0.67^{* *}$ \\
\hline InCOSCO & $5.10^{* *}$ & $-3.70^{* *}$ & $1.71^{* *}$ \\
\hline hWANHAI & -0.18 & 0.61 & $0.67^{* *}$ \\
\hline InHYUNDAI & $12.83^{* *}$ & 3.41 & -1.51 \\
\hline InK-LINE & $-1.24^{* *}$ & 0.38 & $1.58^{* *}$ \\
\hline $\begin{array}{l}* \text { *Significant at the 1\% Level, } \\
\text { *Significant at the 5\% Level }\end{array}$ & & \\
\hline
\end{tabular}

Table 5.

Equilibrium ratios between stocks.

\begin{tabular}{llll} 
Martime Stock & $\boldsymbol{\beta i}$ (InDSV) & $\boldsymbol{\beta 2}$ (InCNI) & $\boldsymbol{\beta 3}$ (InBDI) \\
\hline EVERGREEN & $-1.03^{* *}$ & $1.37^{*}$ & $0.50^{* *}$ \\
\hline HLAG & $-4.53^{* *}$ & -0.41 & $-0.30^{* *}$ \\
\hline YANGMING & $-2.15^{* *}$ & $2.75^{* *}$ & $0.74^{* *}$ \\
\hline WANHAI & $-2.50^{* *}$ & $3.42^{* *}$ & $0.54^{*}$ \\
\hline HYUNDAI & $-8.87^{* *}$ & $15.02^{* *}$ & $2.73^{* *}$ \\
\hline *Significant at the 1\% Level, & & \\
*Significant at the 5\% Level & & \\
\hline
\end{tabular}

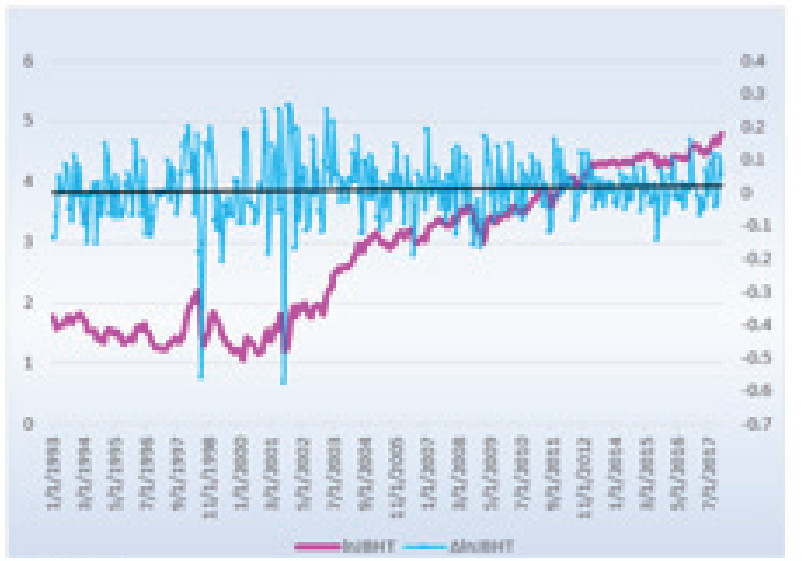

Figure 1.

JBHT Stock Price Levels Versus Changes.

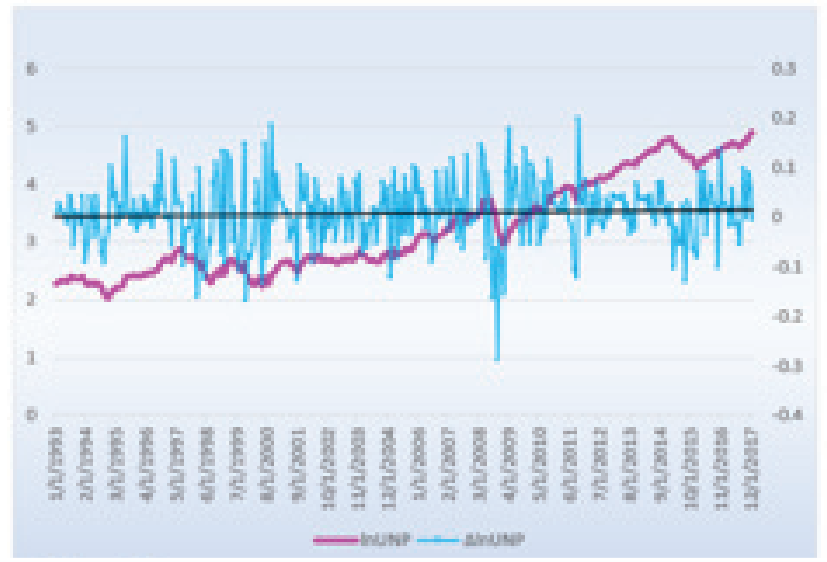

Figure 2.

UNP Stock Price Levels Versus Changes. 
Using Equation 2, the equilibrium ratios $\beta 1$ through $\beta 3$ between the three stocks and the BDI were estimated. Table 4 shows the ratios between the stocks and the BDI that must hold in order for an equilibrium to hold for each maritime stock. For this case, JBHT and UNP are used as the truck and rail stocks. . Table 5 shows the results when DSV and CNI are used in place of JBHT and UNP.

The interpretation of these equilibrium ratios in Table 4 can be illustrated with EVERGREEN in the first row. The coefficient $\beta 1$ for EVERGREEN and JBT is 0.4. To be at an equilibrium, JBHT must be 4 the size of EVERGREEN. If the price of EVERGREEN rises, either their price needs to come down or the price of JBHT must go up in order to maintain this ratio. Similarly, the equilibrium ratios between Evergreen and UNP is one to .43 and the ratio with BDI is one to .33 . All of these ratios must hold for an equilibrium to exist. While the prices of the stocks will diverge from these equilibrium ratios, since these variables are cointegrated, they will always converge back to these ratios.

Figure 3 presents a visual example of cointegration. This graph shows the interrelationship between HLAG and UNP since HLAG went public in 2015. The axes are scaled so that the left axis shows UNP's stock price. The right axis shows HLAG's stock price scaled four to one, so if UNP's price is 100, then HLAG's price is 25 . Thereby anytime the lines cross, they are exactly at a four to one ratio. When UNP's price increases and HLAG's price drops in 2016, they are no longer at a four to one ratio, with UNP hovering above HLAG in the graph. By 2017 they are back at four to one, but later that year they are again out of ratio and HLAG is hovering above UNP. But again, they go back to the four to one ratio. This is an example of what cointegration entails - two series that wander apart, but in the long run move back together at an equilibrium ratio.

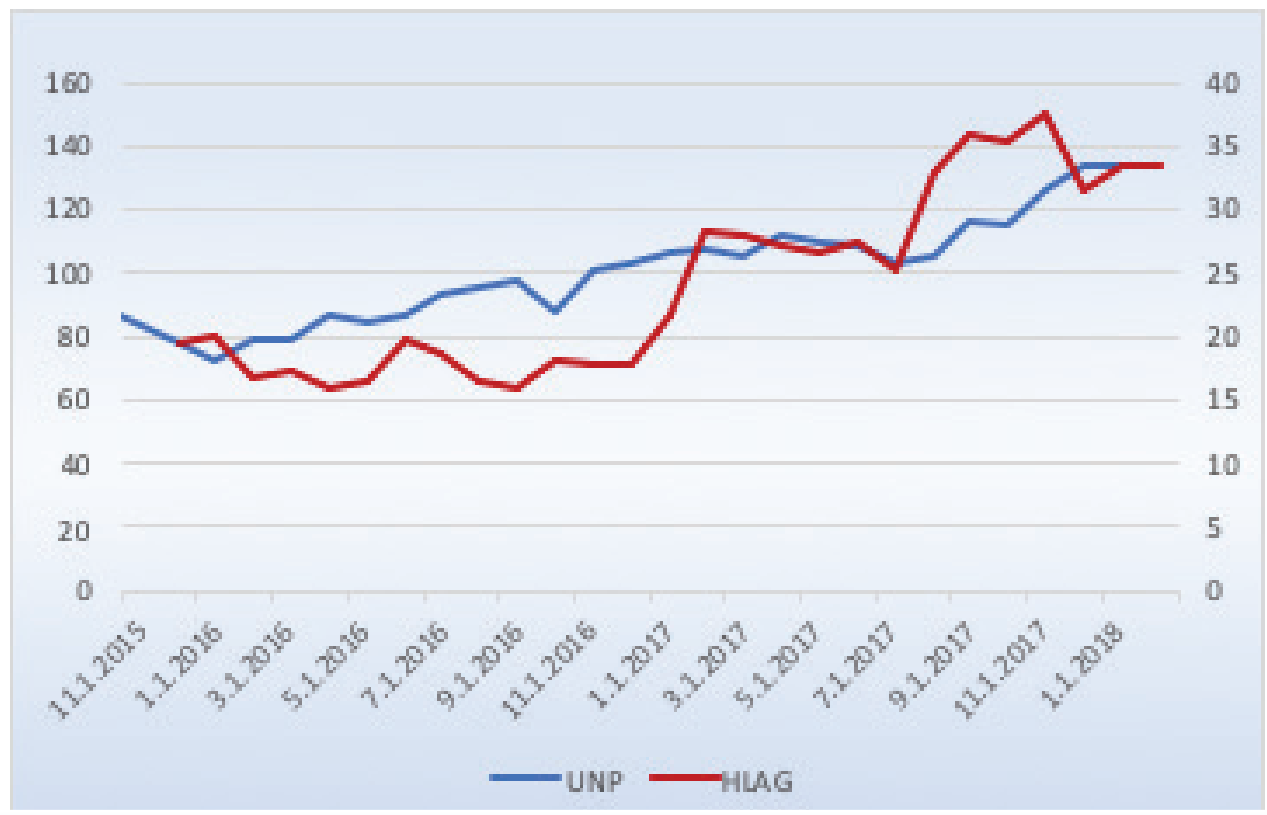

Figure 3.

Contegration Between HLAG and UNP.

Using Equations 3 through 6 and the ratios in Table 3, the degree to which each maritime stock diverges from these equilibrium ratios is calculated. These monthly divergences are the error correction terms (ECT) and are used in the next set of regressions, Equations 3 through 6. An example of these regressions is illustrated in Table 6 with MITSUI, the maritime stock shown to have the best explanatory power. Table 6 presents the results of Equations 3 through 6 .
For Equation 3, we see that none of the explanatory variables significantly predict $\Delta$ InMITSUIT. It appears that Mitsui's stock is unresponsive to movements in other stocks and cannot be predicted. However, with Equation 4 with $\Delta$ InJBHTT as the dependent variable, it can be seen that JB Hunt's stock can be predicted with past values of other variables. First of all, the coefficient for $\Delta$ InMITSUIT-1 is statistically significant .222 which means if Mitsui's stock price increases by $10 \%$ at month T-1, then 
JB Hunt's stock will increase by $2.22 \%$ in the following month T. In other words, Mitsui's stock price this month can help us predict JB Hunt's stock price next month.

Similarly, ECTt-1 has a statistically significant coefficient at -0.036 in Equation 4. Since ECT represents the deviation from the equilibrium, this means that when the stock prices are out of equilibrium, JBHUNT moves back to equilibrium at a rate of $3.6 \%$ per month. Again, JBHUNT can be predicted by examining the prior month's stock prices. The results in Equation 5 are very similar, as they show that UNP can be predicted by looking at pack values of MITSUI, as well as ECT. For Equation 6, BDI is only predicted by past values of BDI. The positive coefficient for ECTt1 indicates that it does not move back to its equilibrium ratio and instead moves independently. So overall, MITSUI can predict JBHT and UNP, but not BDI. No variable can predict MITSUI, indicating that MITSUI is a variable that leads rather than follows the other ones.

Table 6.

Regression results: Equations 4 through 7.

(4) $\Delta$ InMITSUIT

(5) $\triangle \operatorname{lnJBHTT}$

(6) $\triangle \mathrm{InUNPT}$

(7) $\triangle \ln B D I T$

\begin{tabular}{lllll}
\hline ECT $_{\mathrm{T}-1}$ & -0.016 & $-0.036^{*}$ & $-0.027^{* *}$ & $0.184^{* *}$ \\
& $(0.018)$ & $(0.015)$ & $(0.010)$ & $(0.036)$ \\
\hline AlnMITSUI $_{\mathrm{T}-1}$ & 0.081 & $0.222^{* *}$ & $0.100^{*}$ & 0.128 \\
& $(0.074)$ & $(0.062)$ & $(0.043)$ & $(0.147)$ \\
\hline AlniBHT $_{\mathrm{T}-1}$ & 0.073 & 0.059 & 0.043 & 0.181 \\
& $(0.092)$ & $(0.076)$ & $(0.053)$ & $(0.183)$ \\
\hline AlnUNP $_{\mathrm{T}-1}$ & 0.053 & -0.170 & -0.139 & 0.117 \\
& $(0.137)$ & $(0.113)$ & $(0.078)$ & $(0.271)$ \\
\hline AlnBDI $_{\mathrm{T}-1}$ & -0.010 & -0.016 & 0.033 & $0.232^{* *}$ \\
& $(0.036)$ & $(0.030)$ & $(0.020)$ & $(0.071)$ \\
\hline Adjusted R & -0.008 & 0.089 & 0.104 & 0.125 \\
\hline Observations & 215 & 215 & 215 & 215 \\
\hline **Significant at the 1\% level, & & & \\
* Significant at the 5\% level & & & \\
Standard deviations in parentheses & & & \\
\hline
\end{tabular}

The same set of regressions was run for each maritime stock, exhibiting a cointegrating relationship, i.e. the stocks listed in Tables 4 and 5. The results of these regressions are shown in Table 7. Long-term lag stocks refer to stocks that have a significant and negative coefficient for $\mathrm{ECT}_{\mathrm{t}-1}$, as this indicates that the stock moves back to an equilibrium ratio when other stock prices move. Only three maritime stocks meet this criterion - EVERGREEN, NYKA, and HYUNDAI. This indicates that the other seven maritime stocks cannot be predicted by rail and truck stocks. However, in seven out of nine cases UNP does have a positive $\mathrm{ECT}_{\mathrm{t}-1}$ coefficient. This indicates that it can be predicted by the other stocks, including the maritime ones.

Short-term lead/lag relationships refer to whether a lagged first difference (percentage change) can predict a change in another stock in the following month. Only three maritime stocks (MAERSK, NYKA, EVERGREEN) could be predicted based on the previous month's stock price of a rail or truck stock. Overall, only NYKA and EVERGREEN were significantly predictable in both the short-run and long-run. Three maritime stocks (COSCO, MITSUI, K-LINE) were able to predict UNP or JBHT. Overall, the results suggest that in the long run UNP can be predicted from maritime stocks and maritime stocks have short-term predictive power for UNP as well. JBHT, however, is more mixed. Sometimes it is a lead variable that predicts maritime stocks such as EVERGREEN or NYKA. But at other times it is a lag variable that can be predicted by other maritime stocks. 
Table 7.

Regression results: Summary of long-term and short-term causal relationships.

\begin{tabular}{lll} 
Maritime Stock & Long-Term Lag Stocks & $\begin{array}{l}\text { Martine Short-Term Lead/Lag } \\
\text { Relationships }\end{array}$ \\
\hline EVERGREEN & EVERGREEN** & JBHT leads EVERGREEN* \\
\hline MAERSK & UNP* $^{*}$, JBHT $^{* *}$ & UNP leads Maersk $^{*}$ \\
\hline HLAG & UNP $^{* *}$ & \\
\hline MITSUI & UNP $^{* *}$ & MITSUI leads UNP** MITSUI leads JBHT $^{* *}$ \\
\hline NYKA & NYKA $^{* *}$, UNP $^{* *}$ & JBHT leads NYKA* $^{*}$ \\
\hline COSCO & UNP $^{* *}$ & COSCO leads UNP* $^{*}$, COSCO leads BDI $^{*}$ \\
\hline WANHAI & UNP $^{*}$ & \\
\hline HYUNDAI & HYUNDAI* $^{*}$ & \\
\hline K-LINE & UNP $^{*}$, JBHT $^{*}$ & K-LINE leads UNP**
\end{tabular}

The causal relationships between UNP and the maritime stocks are summarized in Figure 4. Based on both long-term and short-term relationships, the overall direction of causality largely goes from maritime stocks to UNP. For six stocks, there is a oneway direction of causality from the maritime stock to UNP, and for one case there is bidirectional causality. Figure 5 summarizes the relationship between JBHT and maritime stocks. The results are more mixed, but in four of the five cases maritime stocks have a causal impact on JBHT. On balance, maritime stocks appear to be able to predict UNP and JBHT much better than these stocks can predict maritime stocks.

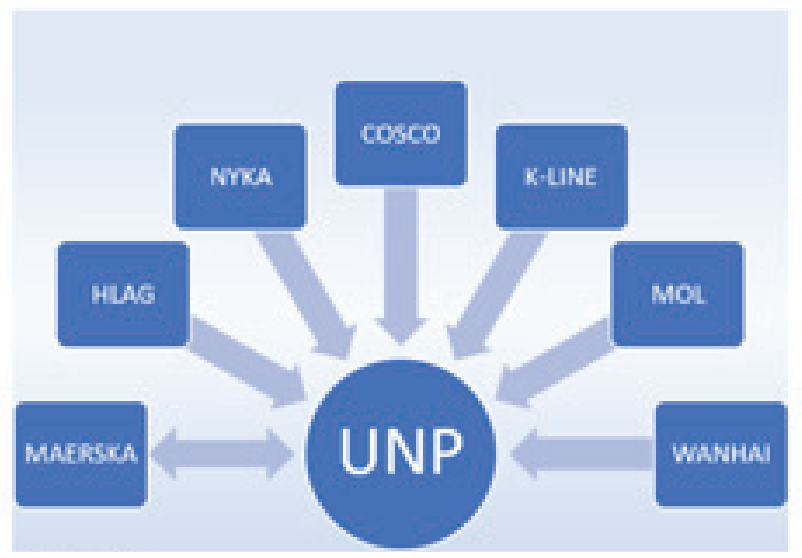

Figure 4.

Direction of causality between UNP and maritime stocks.

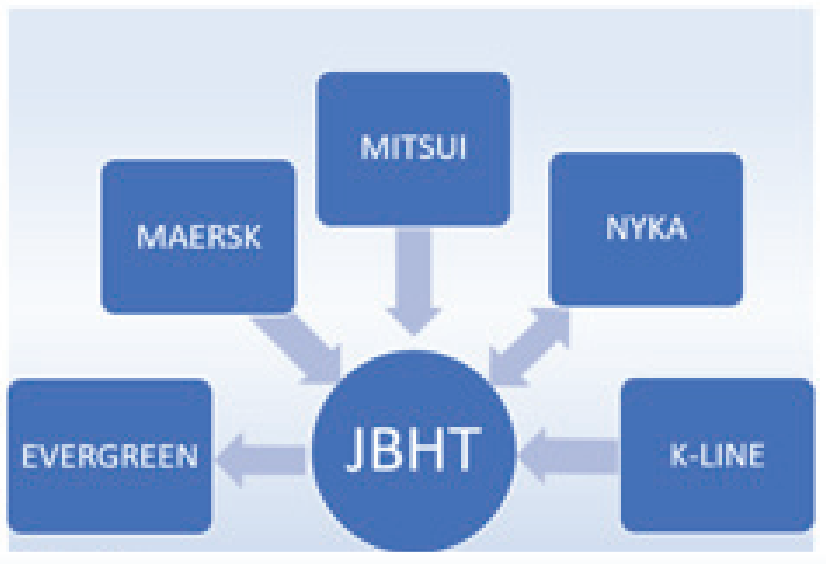

Figure 5.

Direction of causality between JBHT and maritime stocks.

Table 8 presents the regression results with DSV and CNI instead of JBHT and UNP. Since only five maritime stocks showed a significant long-term cointegrating relationship with the other stocks, only the results for these five maritime stocks are shown. The results indicate that in every case DSV has a significant and negative coefficient for $\mathrm{ECT}_{\mathrm{T}-1 \text {, }}$ indicating that it responds when other stock prices move out of equilibrium and thus can be predicted by maritime and other stocks. In addition, in every case the maritime stock also has a significant and negative coefficient for $\mathrm{ECT}_{\mathrm{T}-1}$. This indicates long-term bidirectional causality between DSV and the maritime stocks, with the 
implication that one can predict maritime stocks with DSV and vice versa. $\mathrm{CNI}$ only has a significant coefficient for $\mathrm{ECT}_{\mathrm{T}-1}$ in one case, indicating that it is largely unpredictable by other stocks. In terms of short-term causality, DSV was found to significantly predict EVERGREEN and WANHAI. Figure 6 summarizes the causal relationships between DSV and the maritime stocks, indicating a large degree of bidirectionality. Table 9 presents a summary of all the statistical tests used in the analysis.

Table 8.

Regression results: Summary of long-term and short-term causal relationships.

\begin{tabular}{|c|c|c|}
\hline Maritime Stock & Long-Term Lag Stocks & $\begin{array}{l}\text { Martine Short-Term LeadiLag } \\
\text { Relationships }\end{array}$ \\
\hline EVERGREEN & EVERGREEN ${ }^{* *}$, DSV $^{* *}$ & DSV leads EVERGREEN** \\
\hline HLAG & $\mathrm{HLAG}^{* *}, \mathrm{CNI}^{* *}, \mathrm{DSV}^{* *}, \mathrm{BDI}^{* *}$ & None \\
\hline YANGMING & YANGMENG**, DSV** & None \\
\hline WANHAI & WANHAI**, DSV** & DSV leads WANHAI** \\
\hline HYUNDAI & HYUNDAl $^{* *}, \mathrm{DSV}^{* *}$ & None \\
\hline
\end{tabular}

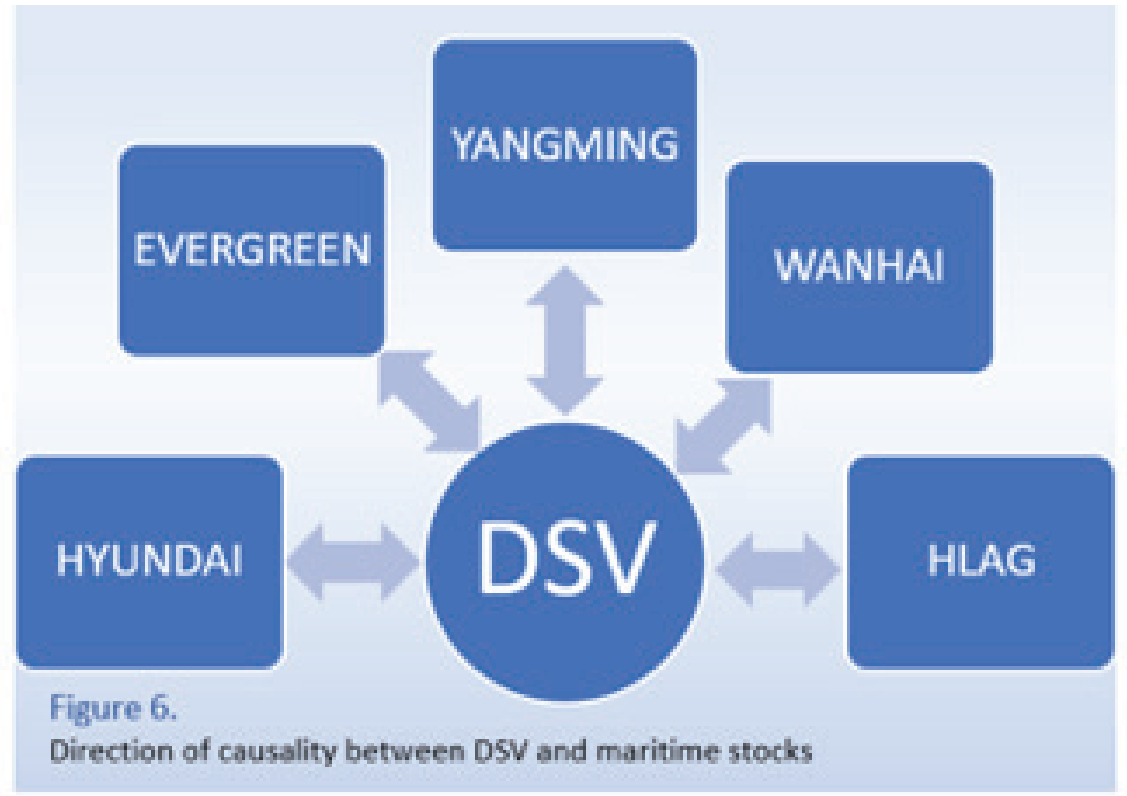

Figure 6

Direction of causality between DSV and maritime stocks. 
Table 9.

Summary of statistical tests.

\begin{tabular}{llll} 
Test & Purpose & Method & Figure/Equation/Table \\
\hline Stationarity & $\begin{array}{l}\text { To examine if data has a constant } \\
\text { mean and variance over time }\end{array}$ & $\begin{array}{l}\text { Phillips-Perron unit root test. See } \\
\text { Equation 1, Table 3, and Figures 1 } \\
\text { and 2. }\end{array}$ & $\begin{array}{l}\text { Equation 3, Table 3, Figures 1 } \\
\text { and 2 }\end{array}$ \\
\hline Cointegration & $\begin{array}{l}\text { To decide if a long-tenn } \\
\text { equilibrium ratio needs to be } \\
\text { accounted for in the regressions }\end{array}$ & $\begin{array}{l}\text { Johansen test for a linear } \\
\text { combination of stock prices that is } \\
\text { stationary. See Figure 3. }\end{array}$ & Figure 3 \\
\hline Granger causality & $\begin{array}{l}\text { To examine the potential causal } \\
\text { Granger Causality direction or } \\
\text { information flow between stock } \\
\text { prices }\end{array}$ & $\begin{array}{l}\text { Regression of past values of stock } \\
\text { price changes on future stock price } \\
\text { changes. See Equations 6 through } \\
\text { 9and Table 6. }\end{array}$ & Equations 1,2, 6-9, Table 6 \\
& & &
\end{tabular}

\section{APPLICATION}

The most straightforward application of the results of this study is for stock market investing. For example, in Equation 5 in Table 6 we can see the coefficient for Mitsui is 0.222 which is statistically significant. Since the data is in logged first differences, the interpretation is that for every amount Mitsui's stock price increases or decreases, the price of JB Hunt's stock will change by $22.2 \%$ of that increase for decrease. This means that if Mitsui's stock price goes up by $10 \%$ in one month, JB Hunts stock will go up by $2.22 \%$ the next month. Similarly, in Equation 6 we can see the coefficient for Mitsui is 1 which is also statistically significant. This indicates that if the price of Mitsui goes up by $10 \%$, the stock price of UNP will go up by $1 \%$. This is just one example. JBHT, UNP, and DSV all have multiple maritime stocks that can significantly predict their future movement.

A more complex stock trading strategy is through the equilibrium ratios found in Table 4. For example, we see that the log of JBHT must be .4 or $40 \%$ of the logged stock price of EVERGREEN. If JBHT's stock price drops below $40 \%$ of EVERGREEN, then either JBHT's stock needs to rise to get back to equilibrium or EVERGREEN's stock price needs to drop. In this case, a strategy called pairs trading (Shen et al., 2020) could be used, where you both take a short position in EVERGREEN and a long position in JBHT. If the stock prices return to equilibrium, either the long or short position will give you a positive return. All the statistically significant coefficients in Tables 4 and 5 could potentially be used to execute a pairs trading strategy.

\section{CONCLUSION}

This paper has shown that the majority of maritime stocks employed in this study can be used to predict three of the four non-maritime transportation stocks that were tested. To a lesser extent, this study has shown that in some cases rail or truck company stocks can be used to predict maritime stocks. These results suggest that investors can potentially apply the methods used in this study to decide which truck and rail companies to invest in. In some cases monthly stock prices can be predicted, such as Mitsui's ability to predict movements in JB Hunt and Union Pacific's stock movements one month in advance. But the majority of the results suggest that only long-run movements in these stocks can be predicted, which could be several months or years. Similarly, previous research has shown that maritime freight rates can impact global markets, but only very gradually (Han et al., 2020). While the methods in this study could be used to make investment decisions, investors should be cautioned that these decisions should be primarily for long-term rather than short-term investments in most cases.

While the cointegration and Granger Causality methods used in this study show us which variables can predict movements in other variables, they are limited in that they do not tell us the precise mechanism by which one variable predicts the other. Maritime stock prices might predict future stock prices, not due to direct causality, but because of other mechanisms. For example, maritime stock prices might contain valuable information about the future direction of the global economy that allows it to predict transportation stock prices. Or it might be a direct mechanism - e.g. maritime shipping might be a complement or substitute for rail and truck shipping, whereby improvements in business for a maritime company might spill over to a rail or truck company.

To further assess the mechanisms which give maritime stocks a predictive power, future research on maritime stocks should be done to see if they also have a predictive power on other economic factors.

Since the BDI has been shown to have a predictive power on such factors as major stock market indices, commodities, 
and GDP (Bakshi, et al., 2011; Erdogan, et al., 2013), maritime stock prices might have similar predictive power on a variety of economic factors. A positive result would indicate that maritime stock prices predict other transportation stock prices as a result of possessing valuable information concerning the world economic trends.

Another limitation of this study is that only stock price and maritime freight rate data was collected. To further investigate the relationship between maritime, rail, and truck stocks, company data should be collected, not only on stock prices but also on revenue and shipping quantities. This data could be used to see if an increase in revenue or quantity shipped by a company has a negative or positive impact on another transportation company. This would help to explain whether or not the predictive power of maritime stocks on other transportation stocks is due to a direct business impact on other companies or due to other factors.

Abbreviations

ECT: Error-correction term

BDI: Baltic Dry Index

JBHT: JB Hunt

UNP: Union Pacific

CNI: Canadian National Railway

\section{REFERENCES}

Abdullah, A. Ç. I. K., Baran, E., \& Ayaz, I. S., 2020. Testing the Efficient Market Hypothesis: A Research on Stocks of Container Shipping Companies, Global Journal of Economics and Business Studies, 9(17), pp. 1-12. Available at: https://dergipark. org.tr/en/pub/gumusgjebs/issue/55948/558942.

Alexandridis, G. et al., 2018. A survey of shipping finance research: Setting the future research agenda. Transportation Research Part E: Logistics and Transportation Review, 115, pp.164-212. Available at: http://dx.doi.org/10.1016/j.tre.2018.04.001.

Alizadeh, A.H. \& Muradoglu, G., 2014. Stock market efficiency and international shipping-market information. Journal of International Financial Markets, Institutions and Money, 33, pp.445-461. Available at:

http://dx.doi.org/10.1016/j.intfin.2014.10.002

Bakshi, G.S., Panayotov, G. \& Skoulakis, G., 2011. The Baltic Dry Index as a Predictor of Global Stock Returns, Commodity Returns, and Global Economic Activity. SSRN Electronic Journal. Available at:

http://dx.doi.org/10.2139/ssrn.1787757.

Beuthe, M., Jourquin, B. \& Urbain, N., 2014. Estimating Freight Transport Price Elasticity in Multi-mode Studies: A Review and Additional Results from a Multimodal Network Model. Transport Reviews, 34(5), pp.626-644. Available at: http://dx.doi.org/10.1080/01441647.2014.946459.

Beuthe, M. et al., 2001. Freight transportation demand elasticities: a geographic multimodal transportation network analysis. Transportation Research Part E: Logistics and Transportation Review, 37(4), pp.253-266. Available at: http://dx.doi.org/10.1016/s1366-5545(00)00022-3.

Bildirici, M.E., Kayıkçı, F. \& Onat, I.Ş., 2015. Baltic Dry Index as a Major Economic Policy Indicator: The Relationship with Economic Growth. Procedia - Social and Behavioral Sciences, 210, pp.416-424. Available at: http://dx.doi.org/10.1016/j.sbspro.2015.11.389.
Choi, K.-H. \& Kim, D.-Y., 2019. The Effect of Baltic Dry Index on the Korean Stock Price Volatility. Journal of Korea Port Economic Association, 35(2), pp.61-75. Available at: http://dx.doi.org/10.38121/kpea.2019.06.35.2.61.

Danthine, J., and Donaldson, J., 2015. Intermediate Financial Theory. Available at: http://dx.doi.org/10.1016/c2010-0-68534-8.

Drobetz, W., Menzel, C. \& Schröder, H., 2016. Systematic risk behavior in cyclical industries: The case of shipping. Transportation Research Part E: Logistics and Transportation Review, 88, pp.129-145. Available at: http://dx.doi.org/10.1016/j.tre.2016.01.008.

Drobetz, W., Schilling, D. \& Tegtmeier, L., 2010. Common risk factors in the returns of shipping stocks. Maritime Policy \& Management, 37(2), pp.93-120. Available at: http://dx.doi.org/10.1080/03088830903533726.

Engle, R.F. \& Granger, C.W.J., 1987. Co-Integration and Error Correction: Representation, Estimation, and Testing. Econometrica, 55(2), p.251. Available at: http://dx.doi.org/10.2307/1913236.

Erdogan, O. et al., 2013. Dynamics of the co-movement between stock and maritime markets. International Review of Economics \& Finance, 25, pp.282-290. Available at: http://dx.doi.org/10.1016/j.iref.2012.07.007.

Fabozzi, F.J. et al., 2014. The Basics of Financial Econometrics. Available at: http://dx.doi.org/10.1002/9781118856406

Farooq, O. \& Aktaruzzaman, K., 2019. Informational role of ownership concentration: evidence from the Casablanca stock exchange. Journal of Islamic Accounting and Business Research, 10(5), pp.726-735. Available at: http://dx.doi.org/10.1108/jiabr-11-2016-0141.

Finke, C. \& Weigert, F., 2017. Does Foreign Information Predict the Returns of Multinational Firms Worldwide? Review of Finance, p.rfw070. Available at: http://dx.doi.org/10.1093/rof/rfw070.

Giannarakis, G. et al., 2017. The effect of Baltic Dry Index, gold, oil and usa trade balance on Dow Jones Sustainability Index World, 7(5), pp. 155-160.

Giannakopoulou, E.N., Thalassinos, E.I. \& Stamatopoulos, T.V., 2015. Corporate governance in shipping: an overview. Maritime Policy \& Management, 43(1), pp.1938. Available at:

http://dx.doi.org/10.1080/03088839.2015.1009185

Granger, C.W.J., 1969. Investigating Causal Relations by Econometric Models and Cross-spectral Methods. Econometrica, 37(3), p.424. Available at: http://dx.doi.org/10.2307/1912791.

Granger, C.W.J. \& Newbold, P., 1974. Spurious regressions in econometrics. Journal of Econometrics, 2(2), pp.111-120. Available at: http://dx.doi.org/10.1016/0304-4076(74)90034-7.

Grelck, M.B. et al., 2009. Diversification Properties of Investments in Shipping. The Journal of Alternative Investments, 12(1), pp.55-74. Available at: http://dx.doi.org/10.3905/jai.2009.12.1.055.

Harris, R., 1995. Using Cointegration Analysis in Econometric Modelling, Hemel Hempstead: Prentice Hall/Harvester Wheatsheaf.

International Maritime Organization, 2020. Challenges. Available at: http://www. imo.org/en/OurWork/TechnicalCooperation/ITCP/Pages/Challenges.aspx.

Jawadi, F., Jawadi, N. \& Cheffou, A.I., 2015. Are Islamic stock markets efficient? A time-series analysis. Applied Economics, 47(16), pp.1686-1697. Available at: http://dx.doi.org/10.1080/00036846.2014.1000535. 
Johansen, S., 1995. Likelihood-Based Inference in Cointegrated Vector Autoregressive Models. Available at: http://dx.doi.org/10.1093/0198774508.001.0001.

Han, L., Wan, L. \& Xu, Y., 2020. Can the Baltic Dry Index predict foreign exchange rates? Finance Research Letters, 32, p.101157. Available at:

http://dx.doi.org/10.1016/j.frl.2019.04.014.

Kasimati, E. \& Veraros, N., 2017. Accuracy of forward freight agreements in forecasting future freight rates. Applied Economics, 50(7), pp.743-756. Available at: http://dx.doi.org/10.1080/00036846.2017.1340573.

Khan, M.Z. \& Khan, F.N., 2020. Estimating the demand for rail freight transport in Pakistan: A time series analysis. Journal of Rail Transport Planning \& Management, 14, p.100176. Available at:

http://dx.doi.org/10.1016/j.jrtpm.2019.100176.

Kyriakou, I. et al., 2017. Freight derivatives pricing for decoupled mean-reverting diffusion and jumps. Transportation Research Part E: Logistics and Transportation Review, 108, pp.80-96. Available at: http://dx.doi.org/10.1016/j.tre.2017.09.002.

Lin, A.J., Chang, H.Y. \& Hsiao, J.L., 2019. Does the Baltic Dry Index drive volatility spillovers in the commodities, currency, or stock markets? Transportation Research Part E: Logistics and Transportation Review, 127, pp.265-283. Available at: http://dx.doi.org/10.1016/j.tre.2019.05.013.

Manoharan, M. \& Visalakshmi, S., 2019. The interrelation between Baltic Dry Index a practical economic indicator and emerging stock market indices. Afro-Asian J. of Finance and Accounting, 9(2), p.213. Available at: http://dx.doi.org/10.1504/aajfa.2019.099483.

McCullough, G.J. \& Hadash, I., 2019. Price Effects in Truck-Competitive Railroad Markets. U.S. Freight Rail Economics and Policy, pp.114-126. Available at: http://dx.doi.org/10.4324/9780429031120-5.

Merikas, A., Gounopoulos, D. \& Nounis, C., 2009. Global shipping IPOs performance. Maritime Policy \& Management, 36(6), pp.481-505. Available at: http://dx.doi.org/10.1080/03088830903346053.

Merikas, A., Gounopoulos, D. \& Karli, C., 2010. Market performance of US-listed Shipping IPOs. Maritime Economics \& Logistics, 12(1), pp.36-64. Available at: http://dx.doi.org/10.1057/mel.2009.18.

Mitchell, D., 2010. Australian Intercapital Freight Demand: An Econometric Analysis, Australasian Transport Research Forum 2010 Proceedings, 29, pp. 1-19. Available at: https://www.australasiantransportresearchforum.org.au/sites/default/files/2010_ Mitchell_A.pdf.
Navin, R.L. ed., 2012. The Mathematics of Derivatives. Available at: http://dx.doi.org/10.1002/9781119197034.

Panayides, P.M., Lambertides, N. \& Cullinane, K., 2013. Liquidity risk premium and asset pricing in US water transportation. Transportation Research Part E: Logistics and Transportation Review, 52, pp.3-15. Available at:

http://dx.doi.org/10.1016/j.tre.2012.11.007.

Rich, J., Kveiborg, O. \& Hansen, C.O., 2011. On structural inelasticity of modal substitution in freight transport. Journal of Transport Geography, 19(1), pp.134-146. Available at:

http://dx.doi.org/10.1016/j.jtrangeo.2009.09.012

Schramm, H.-J. \& Munim, Z.H., 2021. Container freight rate forecasting with improved accuracy by integrating soft facts from practitioners. Research in Transportation Business \& Management, p.100662. Available at: http://dx.doi.org/10.1016/j.rtbm.2021.100662.

Schwarz, G., 1978. Estimating the Dimension of a Model. The Annals of Statistics, 6(2). Available at: http://dx.doi.org/10.1214/aos/1176344136.

Shen, L. et al., 2020. An Evaluation of Pairs Trading in Commodity Futures Markets. 2020 IEEE International Conference on Big Data (Big Data). Available at:

http://dx.doi.org/10.1109/bigdata50022.2020.9377766.

Su, C.-W. et al., 2019. Are there bubbles in the shipping freight market? Maritime Policy \& Management, 46(7), pp.818-830. Available at: http://dx.doi.org/10.1080/03088839.2019.1619946.

Syriopoulos, T. \& Tsatsaronis, M., 2011. The corporate governance model of the shipping firms: financial performance implications. Maritime Policy \& Management, 38(6), pp.585-604. Available at:

http://dx.doi.org/10.1080/03088839.2011.615867.

Syriopoulos, T. \& Bakos, G., 2019. Investor herding behaviour in globally listed shipping stocks. Maritime Policy \& Management, 46(5), pp.545-564. Available at: http://dx.doi.org/10.1080/03088839.2019.1597288.

Yazir, D. \& Sahin, B., 2017. Linear Regression Approach for the Financial Risks of Shipping Industry. TransNav, the International Journal on Marine Navigation and Safety of Sea Transportation, 11(4), pp.635-640. Available at: http://dx.doi.org/10.12716/1001.11.04.09.

Yin, J., Luo, M. \& Fan, L., 2016. Dynamics and interactions between spot and forward freights in the dry bulk shipping market. Maritime Policy \& Management, 44(2), pp.271-288. Available at: http://dx.doi.org/10.1080/03088839.2016.1253884 